\title{
Xylose-Inducible Promoter Tools for Pseudomonas Species and Their Use in Implicating a Role for the Type II Secretion System Protein XcpQ in the Inhibition of Corneal Epithelial Wound Closure
}

\author{
Jake D. Callaghan, ${ }^{a}$ Nicholas A. Stella, ${ }^{a}$ Kara M. Lehner, ${ }^{a}$ Benjamin R. Treat, ${ }^{b}$ Kimberly M. Brothers, ${ }^{a}$ (D) Anthony J. St. Leger, ${ }^{b}$ \\ (D) Robert M. Q. Shanksa \\ aCharles T. Campbell Laboratory of Ophthalmic Microbiology, Department of Ophthalmology, University of Pittsburgh Medical School, Pittsburgh, Pennsylvania, USA \\ bDepartment of Ophthalmology, University of Pittsburgh Medical School, Pittsburgh, Pennsylvania, USA
}

\begin{abstract}
Tunable control of gene expression is an invaluable tool for biological experiments. In this study, we describe a new xylose-inducible promoter system and evaluate it in both Pseudomonas aeruginosa and Pseudomonas fluorescens. The $P_{x u t}$ promoter, derived from the $P$. fluorescens $x u t$ operon, was incorporated into a broadhost-range pBBR1-based plasmid and was compared to the Escherichia coli-derived $P_{B A D}$ promoter using $g f p$ as a reporter. Green fluorescent protein (GFP) fluorescence from the $P_{x u t}$ promoter was inducible in both Pseudomonas species, but not in $E$. coli, which may facilitate the cloning of genes toxic to $E$. coli to generate plasmids. The $P_{x u t}$ promoter was activated at a lower inducer concentration than $P_{B A D}$ in $P$. fluorescens, and higher gfp levels were achieved using $P_{x u t}$. Flow cytometry analysis indicated that $P_{x u t}$ was leakier than $P_{B A D}$ in the Pseudomonas species tested but was expressed in a higher proportion of cells when induced. D-Xylose as a sole carbon source did not support the growth of $P$. aeruginosa or $P$. fluorescens and is less expensive than many other commonly used inducers, which could facilitate large-scale applications. The efficacy of this system was demonstrated by its use to reveal a role for the $P$. aeruginosa type II secretion system gene $x c p Q$ in bacterial inhibition of corneal epithelial cell wound closure. This study introduces a new inducible promoter system for gene expression for use in Pseudomonas species.
\end{abstract}

IMPORTANCE Pseudomonas species are enormously important in human infections, in biotechnology, and as model systems for investigating basic science questions. In this study, we have developed a xylose-inducible promoter system, evaluated it in $P$. aeruginosa and $P$. fluorescens, and found it to be suitable for the strong induction of gene expression. Furthermore, we have demonstrated its efficacy in controlled gene expression to show that a type II secretion system protein from P. aeruginosa, $\mathrm{XcpQ}$, is important for host-pathogen interactions in a corneal wound closure model.

KEYWORDS Pseudomonas, inducible promoter, plasmids, xylose

Pecies of the bacterial genus Pseudomonas are of exceptional importance, not only as infectious agents for a broad range of organisms, including humans and plants (1-4), but also for the valuable role that species of this genus play in biotechnology and basic science $(5,6)$. Inducible gene expression systems are important tools in both biotechnology and basic science that enable tunable expression in the presence of an effector molecule.

Inducible plasmid systems for pseudomonads include the L-arabinose-inducible, AraC-regulated $P_{B A D}$ promoter from Escherichia coli, which is inducible in Pseudomonas aeruginosa (7-9). Whereas this promoter has proven useful for gene expression in
Citation Callaghan JD, Stella NA, Lehner KM, Treat BR, Brothers KM, St. Leger AJ, Shanks RMQ. 2020. Xylose-inducible promoter tools for Pseudomonas species and their use in implicating a role for the type II secretion system protein XcpQ in the inhibition of corneal epithelial wound closure. Appl Environ Microbiol 86:e00250-20. https://doi.org/10 .1128/AEM.00250-20.

Editor Eric V. Stabb, University of Illinois at

Chicago

Copyright $\odot 2020$ American Society for Microbiology. All Rights Reserved.

Address correspondence to Robert M. Q. Shanks, shanksrm@upmc.edu.

Received 31 January 2020

Accepted 8 May 2020

Accepted manuscript posted online 15 May 2020

Published 2 July 2020 
numerous studies, it has been demonstrated to be leaky without induction in $P$. aeruginosa (10). Other inducible promoter systems in $P$. aeruginosa include the laclaPtac and the rhaSR-P $P_{\text {rhaB }}$ promoter $(10,11)$. While lacla-Ptac and rhaSR- $P_{\text {rhas }}$ confer tightly controlled gene expression when inserted into the chromosome (10), the rhaSR- $P_{\text {rhaB }}$ system is large $(>2,000 \mathrm{bp})$, and the lacla-Ptac system uses a high-cost inducer. Therefore, there would be value in the development of a small-size, low-cost system for gene expression from episomal plasmids.

The goal of this study was to develop an episomal-plasmid-based inducible promoter system for Pseudomonas species using pseudomonad-derived DNA. This study describes the evaluation of the Pseudomonas fluorescens xutR- $P_{x u t A}$ promoter system (here designated $P_{x u t}$ ) in both $P$. aeruginos $a$ and $P$. fluorescens. In addition, we use this system to interrogate $P$. aeruginosa host-pathogen interactions, particularly the mechanisms underlying bacterial inhibition of corneal epithelial cell wound closure (12).

\section{RESULTS}

Identification and cloning of a putative xylose-inducible promoter from $\boldsymbol{P}$. fluorescens. A putative xylose metabolism transcription factor gene, Pf101_2304, was identified in the $P$. fluorescens strain Pf0-1 genome by BLAST analysis (13). Recently, the homolog of this gene in $P$. fluorescens strain SBW25 was demonstrated to encode an activator of a xylose metabolism operon and was named XutR by Liu et al. (14). In strain SBW25, the XutR protein was demonstrated to directly and positively regulate transcriptional expression of the adjacent gene, xutA, in a xylose-dependent manner, and bound to a conserved operator site (AAAATC- $\mathrm{N}_{15}$-GATTTT) upstream of xutA (14). In the SBW25 genome, the intergenic region between xutR and xutA is $139 \mathrm{bp}$ long, whereas it is 182 to 188 bp long in $P$. fluorescens strain Pf0-1, depending on whether a TTG or an ATG for xutA is the start codon. Other differences in the intergenic region between strains SBW25 and Pf0-1 include a direct repeat of CCAAGAACAACAA just upstream of the ribosome binding site in Pf0-1 that is present in a single copy in SBW25. $A$ schematic diagram and sequence for the intergenic region of strain $\mathrm{PfO}-1$ are presented in Fig. $1 \mathrm{~A}$ and $\mathrm{B}$. The $x u t R$ and intergenic regions with the promoter for $x u t A$ (here designated $P_{x u t}$ ) from strain PfO-1 were cloned into a pBBR1-based broad-hostrange plasmid, pMQ132 (11), with gfp placed under the control of $P_{x u t}$ (Table 1). A diagram of the resulting plasmid, pMQ578, is shown in Fig. $1 \mathrm{C}$ and Fig. S1A in the supplemental material.

The pMQ578 plasmid has an RP4 oriT sequence for conjugal transfer, the aacC-1 gentamicin resistance marker, and a selectable marker and replicon for Saccharomyces cerevisiae to allow for in vivo yeast cloning (8). We used a previously described plasmid with the $E$. coli $P_{B A D}$ promoter driving $g f p$, pMQ80 (8), as a comparison promoter, since the $P_{B A D}$ promoter is frequently used for gene expression in E. coli and Pseudomonas species. The resulting plasmids were used to characterize $P_{x u t}$ expression in $E$. coli and two species of Pseudomonas.

Characterization of $\boldsymbol{P}_{\text {xut }}$ expression in $E$. coli, $\boldsymbol{P}$. aeruginosa, and $\boldsymbol{P}$. fluorescens. To evaluate $P_{\text {xut }}$ and $P_{B A D}$ expression, pMQ578 and pMQ80 were introduced into $E$. coli strain S17-1, $P$. aeruginosa strain PA14, and $P$. fluorescens strain Pf0-1. Increasing doses of L-arabinose and D-xylose were added to cultures (optical density at $600 \mathrm{~nm}\left[\mathrm{OD}_{600}\right]$, 0.01 ), and the cultures were analyzed for green fluorescent protein (GFP) fluorescence using a fluorometer after $25 \mathrm{~h}$ of incubation at $30^{\circ} \mathrm{C}$ or $37^{\circ} \mathrm{C}$. After the addition of an inducer, with $E$. coli, no fluorescence was measured with $P_{x u t}-g f p$ compared to the absence of an inducer, whereas $P_{B A D}$ was inducible at low concentrations $(0.1 \mathrm{mM})$ of L-arabinose (Fig. 2A). In $P$. aeruginosa, both $P_{\text {xut }}$-based expression and $P_{B A D}$-based expression were dose dependent, and the $P_{x u t}$ promoter was slightly stronger than $P_{B A D}$ at intermediate inducer doses (Fig. 2B). With $P$. fluorescens, both promoters were inducible, but the $P_{x u t}$ promoter was inducible at lower concentrations than the $P_{B A D}$ promoter and was stronger at all doses (Fig. 2C).

The expression of both promoters was tested over time using $10 \mathrm{mM}$ inducer (Fig. $3 \mathrm{~A}$ to $\mathrm{C}$ ). Cultures with an inducer were started at an $\mathrm{OD}_{600}$ of 0.01 and were allowed 


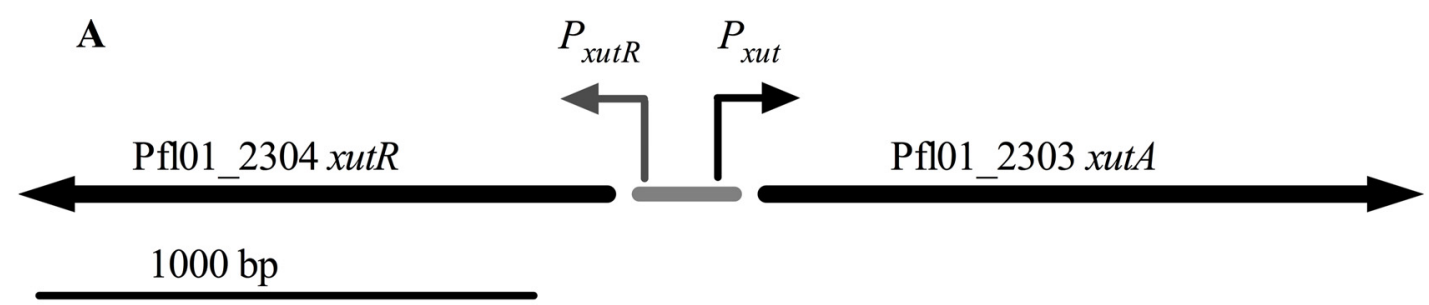

B

CACAGACTAGGCGCGCAGAGGGCGAATCTCAATACGCAAAATCGCACTGCGT GTTGGTGATTTTCGTAATCGGCAGGCACAGGGCCGTTGCTAGTATCGGGACA CGCC-CAAGAACAACAA-CAAGAACAACAa-gga-N${ }_{8}$-ATG

C

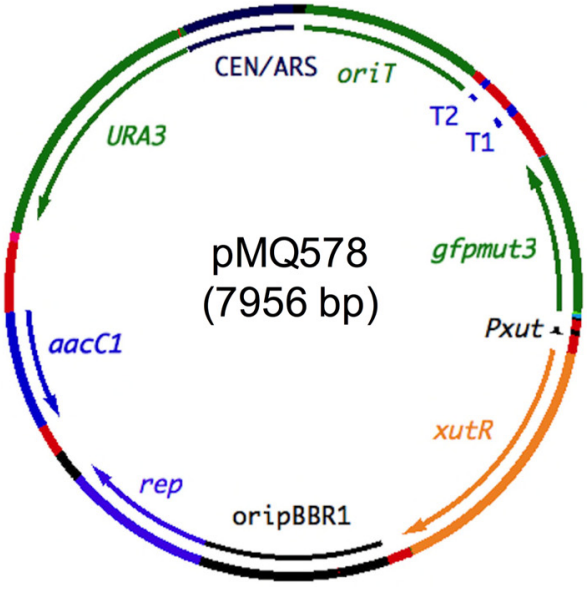

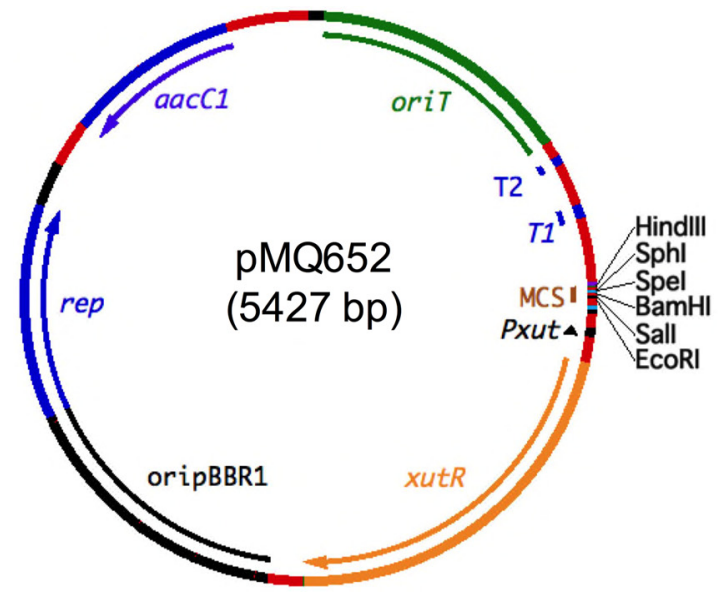

FIG 1 Xylose repressor genomic region from P. fluorescens strain Pf0-1. (A) Genetic map of the xutR-xutA region. The shaded bar represents the 188-bp intergenic region. (B) DNA sequence of the $P_{\text {xut }}$ promoter upstream of Pf101_2303. The conserved operator inverted repeats are shown in boldface, and the -35 and -10 regions for the xutA promoter $\left(P_{x u t}\right)$ are underlined. A direct repeat of $13 \mathrm{bp}$ is shown in italics. A putative ribosome binding site 9 to 12 bp upstream of the start codon is shown in lowercase. (C) Schematic diagrams of select plasmids used in this study.

to grow at $30^{\circ} \mathrm{C}$. Samples were removed and analyzed for GFP fluorescence over time. GFP fluorescence was largely undetected until $6 \mathrm{~h}$ postinduction and was maximal at the final time point $(25 \mathrm{~h})$. The highest fluorescence levels were observed with PfO-1 and $P_{\text {xut }}$ (pMQ578) at $25 \mathrm{~h}$ (Fig. 3C).

TABLE 1 Strains and plasmids used in this study

\begin{tabular}{|c|c|c|}
\hline Strain or plasmid & Description & Reference or source \\
\hline \multicolumn{3}{|l|}{ Strains } \\
\hline S17-1 $\lambda$-pir & E. coli laboratory strain & 46 \\
\hline PIC3611 & S. marcescens, wild type & Presque Isle Cultures \\
\hline PAO1 & P. aeruginosa, wild type & 47 \\
\hline PA14 & P. aeruginosa UCBPP-PA14, wild type & 48 \\
\hline PAC & P. aeruginosa, keratitis isolate & 49 \\
\hline Pfo-1 & P. fluorescens wild-type strain & 50 \\
\hline \multicolumn{3}{|l|}{ Plasmids } \\
\hline pMQ80 & Shuttle vector, pRO1600 with $P_{B A D}-g f p m u t 3$ & 8 \\
\hline pMQ132 & Shuttle vector, $\mathrm{pBBR} 1 ; P_{\text {lac }}-\mathrm{lacZ}$ aacC-1 & 11 \\
\hline pMQ414 & Shuttle vector, RSF1010; $P_{\text {nptII }}$-tdtomato aacC-1 & 43 \\
\hline pMQ578 & pMQ132 with xutR-P $P_{x u t}$-gfp replacing $P_{\text {lac }}-l a c Z$ & This study \\
\hline pMQ643 & pMQ578 with tdtomato replacing gfp & This study \\
\hline pMQ644 & pMQ578 with $x c p Q$ from PA14 replacing $g f p$ & This study \\
\hline pMQ650 & pMQ578 with multicloning site replacing $g f p$ & This study \\
\hline pMQ652 & pMQ650 with yeast replicon removed & This study \\
\hline
\end{tabular}



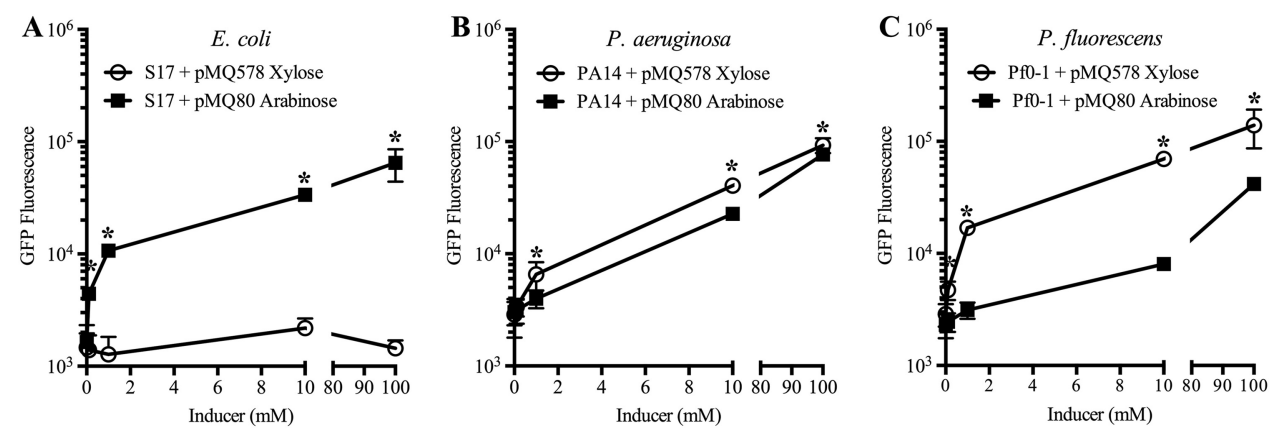

FIG 2 Comparison of the $P_{B A D}$ and $P_{x u t}$ promoters in E. coli and Pseudomonas species. Shown is the expression of gfpmut3 from the two different promoters in a pBBR1-based plasmid. Cultures were prepared in LB medium with a range of inducer concentrations and were grown at $30^{\circ} \mathrm{C}$ for $25 \mathrm{~h}$. Means and standard deviations are shown (n, $\geq 5$ independent cultures). $P_{x u t}$ was not inducible in E. coli and was inducible at lower inducer concentrations than $P_{B A D}$ in $P$. fluorescens. The pMQ578 plasmid has $P_{x u t}-g f p$, and pMQ80 has $P_{B A D}-g f p$. Asterisks indicate statistically significant differences $(P<0.05)$ between groups by Student's $t$ test.

The fold induction of GFP fluorescence was calculated for cultures with $10 \mathrm{mM}$ inducer relative to no inducer. For $P_{B A D}$, the highest induction was for $E$. coli, with a $46 \pm 36$-fold increase, compared to $19 \pm 3$-fold and $27 \pm 9$-fold for PfO- 1 and PA14, respectively. With $P_{\text {xut }}$ GFP levels were unchanged for $E$. coli, with a ratio of $1.03 \pm 0.2$ for $10 \mathrm{mM}$ xylose relative to no xylose, but were $51 \pm 22$-fold and $38 \pm 20$-fold increased for Pf0-1 and PA14, respectively.

The $P_{x u t}$ promoter was evaluated in additional $P$. aeruginosa isolates: the widely used strain PAO1 and the clinical keratitis isolate PAC. With $10 \mathrm{mM}$ xylose, GFP fluorescence in both strains was induced and notably higher than that observed for strain PA14 at the same concentration (compare Fig. S2A with Fig. 5B). The fold induction was calculated and was found to be highest for PAO1 among the three strains, at 55-fold with xylose relative to no inducer (Fig. S2B).

Because $P$. aeruginosa is often studied at $37^{\circ} \mathrm{C}$ due to its role as a human pathogen, we tested the inducibility of $P_{x u t}$ at $37^{\circ} \mathrm{C}$ with xylose $(10 \mathrm{mM})$ by using strains PAO1 and PA14. In results similar to those obtained at $30^{\circ} \mathrm{C}$, xylose induced GFP production at $37^{\circ} \mathrm{C}$. No significant differences were found between the two temperatures in terms of fold induction for either strain, with $>50$-fold induction for PAO1 and 23- to 35-fold induction for PA14 (Fig. S3).

The utilization of an inducer as a carbon source by bacteria can reduce the efficacy of the inducer in a culture over time. We tested the abilities of PA14 and Pf0-1 to grow

A

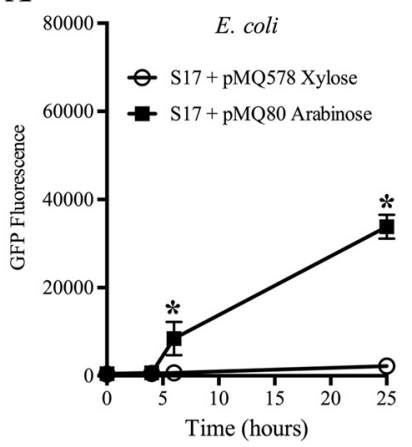

B

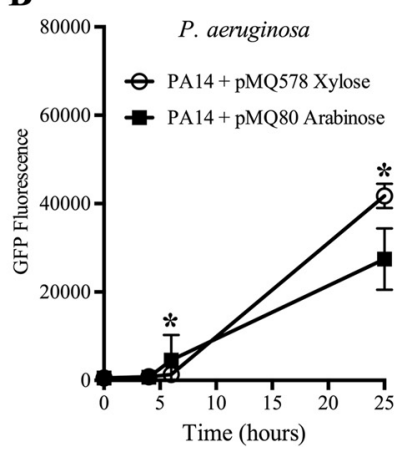

C

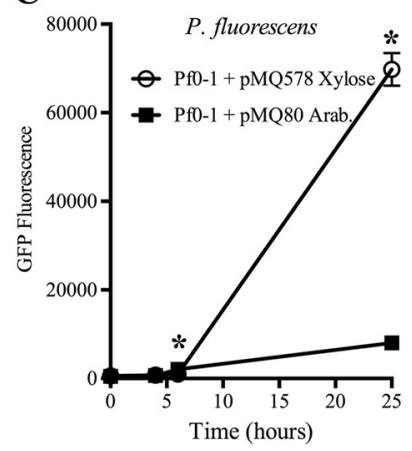

FIG 3 Expression of the $P_{B A D}$ and $P_{x u t}$ promoters in Pseudomonas species and E. coli over time with $10 \mathrm{mM}$ inducer. Shown is the expression of gfpmut3 over time from the two different promoters in a pBBR1-based plasmid. Cultures were prepared in LB medium with an inducer $(10 \mathrm{mM})$ and were grown at $30^{\circ} \mathrm{C}$. Means and standard deviations are shown ( $n, \geq 4$ independent cultures for $E$. coli; $n, 6$ for Pseudomonas species). The pMQ578 plasmid has $P_{x u t}-g f p$, and pMQ80 has $P_{B A D}-g f p$. Xylose was used as an inducer for pMQ578, and arabinose was used for pMQ80. Asterisks indicate statistically significant differences $(P<0.05)$ between groups by Student's $t$ test. 


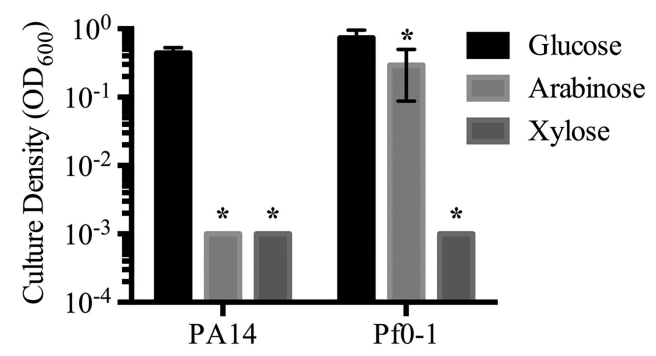

FIG 4 The Pseudomonas species tested do not use D-xylose as a sole carbon source. Cultures were incubated in M9 minimal medium with the indicated sugars at $10 \mathrm{mM}$ for $25 \mathrm{~h}$ at $30^{\circ} \mathrm{C}$. Means and standard deviations are shown ( $n, 6$ independent cultures). Asterisks indicate significant differences from the glucose group $(P<0.05)$ by ANOVA with Tukey's posttest.

in minimal medium with L-arabinose or D-xylose as a sole carbon source at $10 \mathrm{mM}$. Glucose at $10 \mathrm{mM}$ was used as a positive control (Fig. 4). After $24 \mathrm{~h}$ of growth at $30^{\circ} \mathrm{C}$, culture density was measured with a spectrophotometer. Pf0-1 grew with arabinose or glucose, but not with xylose, as a sole carbon source. PA14 grew only with glucose as a carbon source.

Ribose was also shown to be an inducer of $P_{x u t}$ in strain SBW25 (14); therefore, we evaluated ribose as an inducer of bacteria with pMQ578 (Fig. 5). After $25 \mathrm{~h}$ of growth at $30^{\circ} \mathrm{C}$, PA14 showed a $19 \%$ increase in GFP fluorescence with $10 \mathrm{mM}$ ribose relative to no ribose, and a $93 \%$ increase was observed with $100 \mathrm{mM}$ ribose $(1,723 \pm 219$ relative fluorescence units [RFU] without ribose, 2,050 \pm 265 RFU with $10 \mathrm{mM}$, and $3,335 \pm 464$ RFU with $100 \mathrm{mM}$ ). For Pf0-1, we observed a $25 \%$ increase in fluorescence at $10 \mathrm{mM}$ and a $41 \%$ increase at $100 \mathrm{mM}$ ribose $(2,074 \pm 172 \mathrm{RFU}$ without ribose, $2,597 \pm 200 \mathrm{RFU}$ with $10 \mathrm{mM}$, and 2,919 $\pm 219 \mathrm{RFU}$ with $100 \mathrm{mM}$ ). These findings suggest that ribose would have limited utility as an inducer of $P_{x u t}$ relative to xylose in the two strains tested unless controlled, low levels of gene expression are required for an experiment (Fig. 5A).

We further tested whether ribose would have a negative impact on induction by xylose (Fig. 5B). P. aeruginosa with pMQ578 was exposed to xylose and ribose independently or as a mixture, and the GFP fluorescence levels of cultures incubated with xylose alone or both xylose and ribose at $10 \mathrm{mM}$ were indistinguishable $(P,>0.05$ by

A

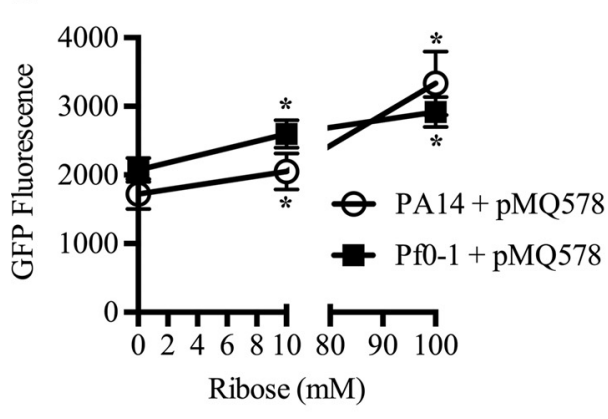

B

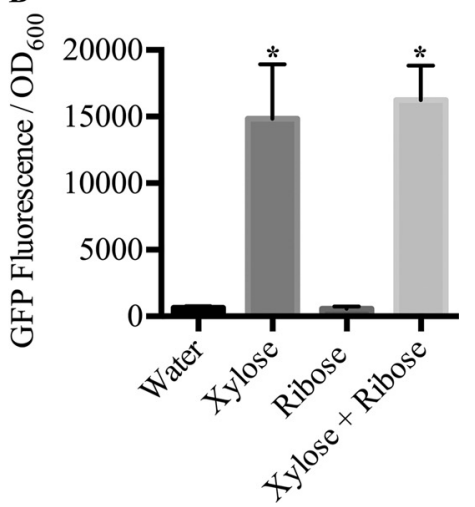

FIG 5 Evaluation of ribose for induction of the $P_{x u t}$ promoter in two Pseudomonas species. Shown is the expression of gfpmut3 in a pBBR1-based plasmid. Cultures were prepared in LB medium with a range of inducer concentrations and were grown at $30^{\circ} \mathrm{C}$ for $25 \mathrm{~h}$. Means and standard deviations are given ( $n$, 6 independent cultures). (A) $P_{\text {xut }}$-based GFP expression was minimally induced by different ribose concentrations. Asterisks indicate significant differences compared to the no-ribose group as determined by Student's $t$ test $(P<0.05)$. (B) Ribose $(10 \mathrm{mM})$ did not alter the ability of xylose $(10 \mathrm{mM})$ to activate $P_{x u t}$-based GFP expression in $P$. aeruginosa strain PA14. Asterisks indicate significant differences compared to the water group as determined by ANOVA with Tukey's posttest $(P<0.05)$. 


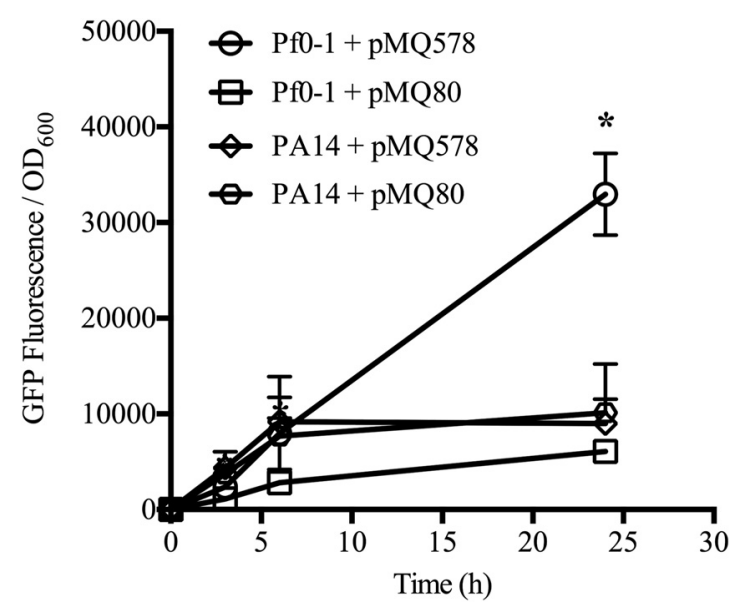

FIG 6 Stationary-phase induction of the $P_{B A D}$ and $P_{x u t}$ promoters in Pseudomonas species. Bacteria were grown overnight in LB broth, washed, and adjusted to an $\mathrm{OD}_{600}$ of 2.0 in PBS with an inducer at $10 \mathrm{mM}$. GFP fluorescence was measured over time. Means and standard deviations are given $(n, 3$ to 4 independent cultures). $P_{x u t}$ was more highly inducible in $P$. fluorescens than in $P$. aeruginosa during stationary phase. $P_{x u t}$ and $P_{B A D}$ were indistinguishable in $P$. aeruginosa. The pMQ578 plasmid has $P_{x u t}-g f p$, and pMQ80 has $P_{B A D}-g f p$. The asterisk indicates a statistically significant difference $(P<0.05)$ by Student's $t$ test between normalized fluorescence levels for PfO- 1 with different plasmids; there were no differences between plasmids in fluorescence levels for PA14. At 25 h, Pf0-1 with pMQ578 produced significantly more fluorescence than PA14.

analysis of variance [ANOVA]), demonstrating that ribose does not prevent the induction of the xut promoter by xylose under the conditions tested.

A similar lack of induction of the $P_{x u t}$ promoter was observed with the Serratia marcescens laboratory strain PIC3611. GFP fluorescence was measured at $727 \pm 144$ RFU with xylose $(10 \mathrm{mM})$ and at $488 \pm 320 \mathrm{RFU}$ without xylose $(P=0.22 ; n=4)$. Similar results were observed in preliminary experiments with Klebsiella pneumoniae and another E. coli strain, MIC4100. These data suggest that, for reasons unknown at this time, $P_{x u t}$ is not expressed in the Enterobacteriaceae.

Comparison of $P_{B A D}$ and $P_{x u t}$ for induction of genes during stationary phase. Next, we investigated whether the $P_{B A D}$ and $P_{x u t}$ promoters were responsive to inducers for cultures in the stationary phase (Fig. 6). We tested the expression of $P_{B A D}-g f p$ and $P_{\text {xut }}$-gfp in stationary-phase cultures to which an inducer was added $(10 \mathrm{mM})$ as a function of time. Pf0-1 and PA14 cultures were grown overnight, washed with phosphate-buffered saline (PBS) to remove residual LB medium, and diluted to an $\mathrm{OD}_{600}$ of 2 in PBS with an inducer. While we do not expect researchers to culture bacteria in PBS for gene expression experiments, PBS was used to prevent significant additional growth and to keep the bacteria in a stationary-phase-like state. Modest induction was shown by $6 \mathrm{~h}$ in stationary-phase cultures incubated in PBS relative to actively growing cultures (Fig. 6). At the final time point, $P_{x u t}$ in Pf0-1 demonstrated the greatest induction of GFP fluorescence, with $5.5 \pm 1$.4-fold higher fluorescence than Pf0-1 with $P_{B A D}$ (Fig. 6). This suggests that the $P_{x u t}$ promoter could be used in stationary-phase cultures, and perhaps biofilms, for the expression of desired genes.

Flow cytometry analysis of promoter activity in Pseudomonas species. Previous studies have indicated that under many conditions, the $P_{B A D}$ promoter is expressed only in a subset of cells of an induced population of E. coli (15-17). Here, we evaluated the $P_{B A D}$ and $P_{x u t}$ promoters in PA14 and Pfo- 1 by using flow cytometry analysis to assess promoter leakiness and to determine the frequency of cells in which gene expression is activated upon the addition of a moderate level of an inducer $(10 \mathrm{mM})$. The data in Fig. 7 and Fig. $8 \mathrm{~A}$ demonstrate a higher level of leakiness for $P_{x u t}$ than for $P_{B A D}$ in both PA14 and Pf0-1. For both species, the $P_{x u t}$ promoter produced higher fluorescence intensity in induced GFP-positive cells than the $P_{B A D}$ promoter (2.5 \pm 8 -fold and $2.3 \pm 0.5$-fold for $P$. fluorescens and $P$. aeruginosa, respectively) 

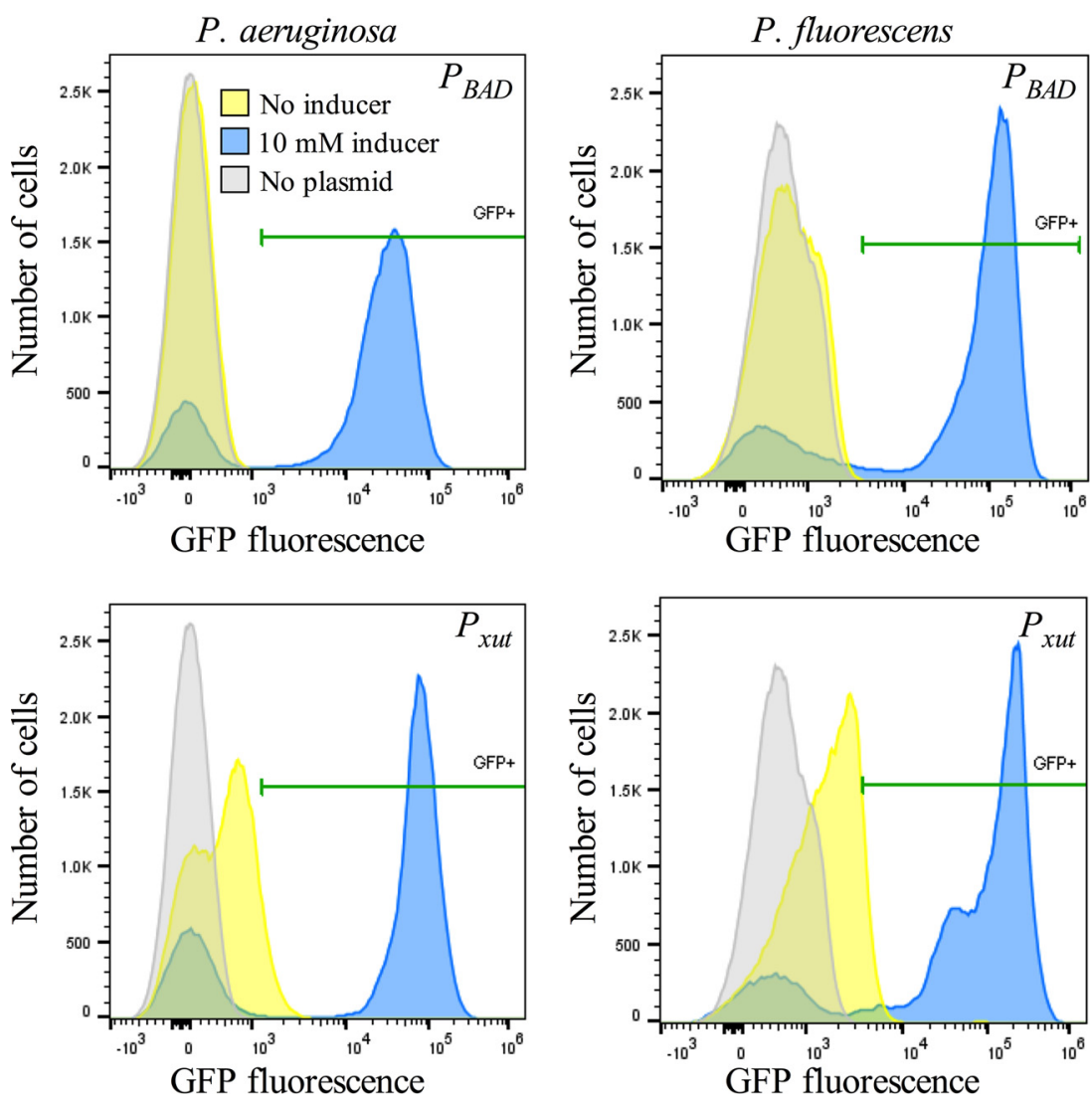

FIG 7 Flow cytometry analysis of $P_{B A D}$ and $P_{x u t}$ promoter-driven GFP expression in Pseudomonas species indicates increased leakiness and increased proportions of bacteria expressing GFP with an inducer. The expression of gfpmut3 from the two different promoters was measured by flow cytometry. Cultures were prepared in LB medium with an inducer $(10 \mathrm{mM})$ and were grown at $30^{\circ} \mathrm{C}$. Gray areas represent PA14 or Pf0-1 with no plasmid, used to determine background levels. Yellow peaks represent bacteria with pMQ578 or pMQ80 without an inducer, used to indicate leakiness. Blue (and green) peaks represent bacteria with pMQ578 or pMQ80 and with an inducer. The pMQ578 plasmid has $P_{x u t}-g f p$, and pMQ80 has $P_{B A D^{-}}$ffp. Xylose was used as an inducer for pMQ578, and arabinose was used for pMQ80. Levels of GFP fluorescence above those for bacteria without a plasmid were used to determine the positive cutoff (noted as GFP+); horizontal green bars indicate positive values. Results of a representative experiment are shown ( $n, \sim 100,000$ cells per group).

(Fig. 8B). Higher fluorescence intensity was observed for Pf0-1 with both promoters, but this may be due to the larger cell size of Pf0- 1 than of PA14 $(P,<0.001$ by ANOVA with Tukey's posttest). The cell length for PA14 was measured at $1.8 \pm 0.5$ or $1.6 \pm 0.4 \mu \mathrm{m}$ when the strain was grown in LB with xylose or arabinose at $10 \mathrm{mM}$, respectively $(n$, $\geq 50$ cells per group). The cell length for PfO- 1 was measured at $2.5 \pm 0.7$ or $2.4 \pm 0.6 \mu \mathrm{m}$ when the strain was grown in LB with xylose or arabinose at $10 \mathrm{mM}$, respectively ( $n, \geq 50$ cells per group).

Additional shuttle vectors with $\boldsymbol{P}_{\text {xut }}$. The $\mathrm{pMQ} 578$ vector with $P_{x u t}$-gfp did not have a convenient restriction site at the $5^{\prime}$ end of the gfp gene, which would impede the replacement of $g f p$ with another gene using traditional cloning methods. To make more user-friendly constructs, the gfp gene was replaced with tdtomato flanked by restriction sites to produce $\mathrm{PMQ} 643$ and with a multicloning site containing six unique restriction sites to produce pMQ650 (Table 1 and Fig. S1). The pMQ643 plasmid was introduced into Pf0-1, which was grown with or without xylose $(10 \mathrm{mM})$. The culture with xylose was significantly brighter than the culture without xylose $(P, 0.016$ by an unpaired $t$ test); tdTomato fluorescence $/ \mathrm{OD}_{600}$ values for cultures with xylose were $1.3 \times 10^{5} \pm 7.2 \times 10^{4}$ versus $2.0 \times 10^{3} \pm 1.7 \times 10^{3}$ for the same culture conditions without xylose. 
A

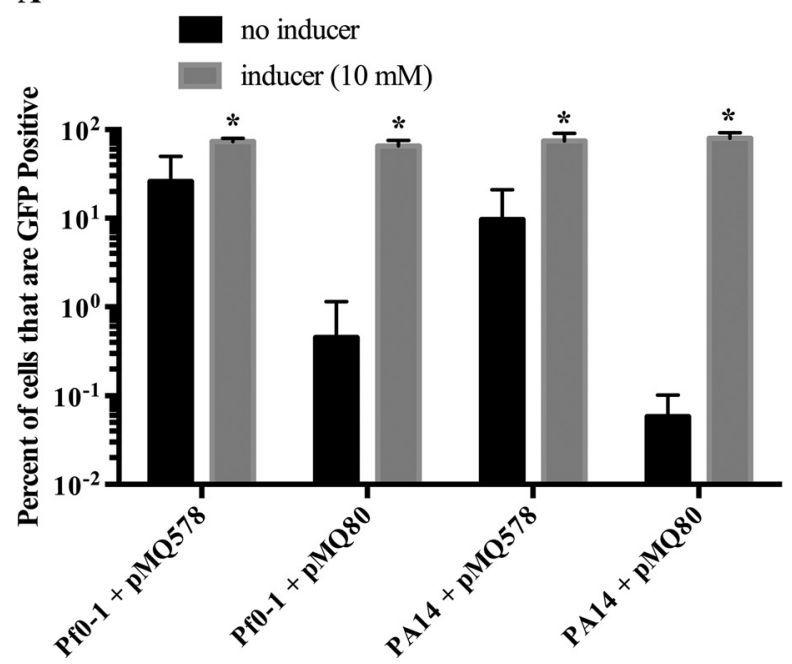

B

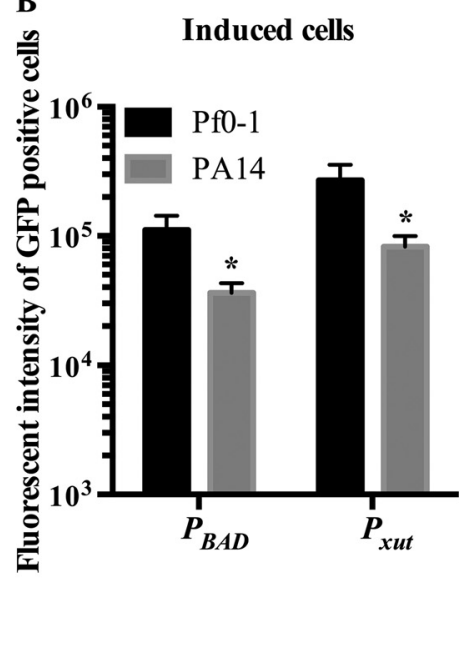

FIG 8 Analysis of promoter leakiness and strength using flow cytometry. GFP expression in Pseudomonas species was analyzed by flow cytometry $(n=7)$. (A) The percentage of GFP-positive cells was determined relative to the level for bacteria without a GFP plasmid. Means and standard deviations are shown. pMQ578 has $P_{x u t}$ and pMQ80 has $P_{B A D}$, driving $g f p$ expression. Asterisks indicate significant differences $(P<0.05)$ from the no-inducer group by Student's $t$ test. (B) Fluorescence intensity of GFP-positive cells that have been induced (inducer concentration, $10 \mathrm{mM}$ ). Means and standard deviations are shown. Asterisks indicate significant differences $(P<0.05)$ between species by Student's $t$ test.

The pMQ650 plasmid was additionally modified by removing the yeast replicon for the benefit of researchers who do not use yeast recombineering. The resulting plasmid, pMQ652, is $5.4 \mathrm{kbp}$ rather than $7.3 \mathrm{kbp}$ (Table 1, Fig. 1C, and Fig. S1B).

Use of the $\boldsymbol{P}_{\text {xut }}$ promoter system to evaluate the impact of $\boldsymbol{P}$. aeruginosa corneal epithelial cell wound closure in vitro. A previous study demonstrated that secreted factors from $P$. aeruginosa strain PA14 could inhibit corneal cell migration and wound healing (12). To gain insight into the mechanism by which a secreted factor(s) from $P$. aeruginosa inhibits corneal wound healing, we first heat-treated normalized secretomes from strain PA14. Whereas unheated secretomes inhibited wound healing, those heated for $10 \mathrm{~min}$ at $95^{\circ} \mathrm{C}$ were unable to inhibit corneal cell migration (data not shown). This result suggested that the inhibitory secreted factor was a heat-labile molecule, such as a protein.

$P$. aeruginosa has numerous secretion systems. We reasoned that the secreted inhibitor factor was unlikely to be secreted by type III or type VI secretion systems, because contact between $P$. aeruginos $a$ and the corneal cells was not necessary for the cell migration phenotype (only culture filtrates were used). Because many enzymes are secreted through the type II secretion system of $P$. aeruginosa (18), we used a strain deficient in XcpQ to test whether the type II secretion system was required for inhibiting cell migration. The XcpQ protein is an essential component of the type II secretion system and forms part of the outer membrane pore (18).

Unlike wild-type PA14 culture filtrates, those from a previously described $\triangle x c p Q$ derivative of PA14 (19) were unable to block cell migration (Fig. 9). Expression of $x c p Q$, but not $g f p$ (used as a negative control) from $P_{x u t}$, was able to restore the cell migration inhibition phenotype to the $x c p Q$ mutant in a $\mathrm{D}$-xylose-dependent manner; that is, 50 $\mathrm{mM}$ (but not $5 \mathrm{mM}$ ) D-xylose was sufficient to complement the cell migration inhibition phenotype (Fig. 9). Importantly, as a control, D-xylose (50 mM) did not restore the cell migration inhibition phenotype to the $\triangle x c p Q$ mutant that did not have a plasmid, indicating that $\mathrm{D}$-xylose alone was not responsible for the phenotype in the absence of the $x c p Q$ plasmid (data not shown). These results indicate that the $P$. aeruginosa type II secretion system is necessary for the inhibition of corneal wound healing and demonstrate the utility of the $P_{x u t}$ system for studying Pseudomonas biology. 
Initial Wound

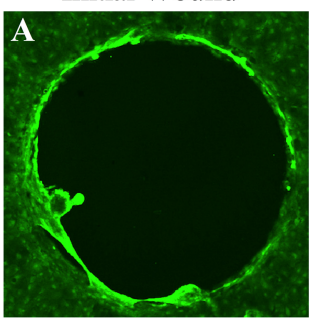

PA14 + pMQ578 $50 \mathrm{mM}$

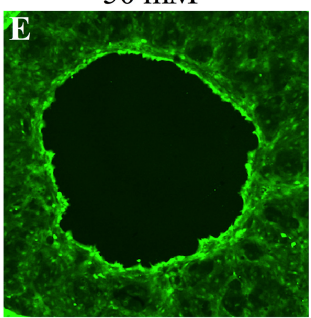

Medium Control

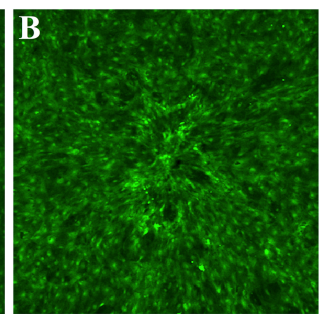

$\triangle x c p Q+\mathrm{pMQ} 578$

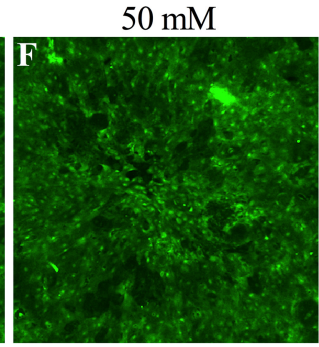

PA14

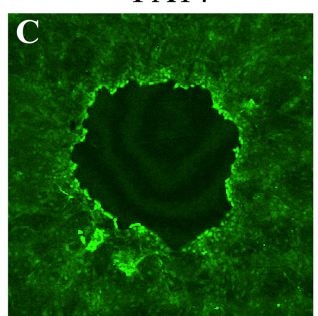

$\triangle x c p Q+$ pMQ644

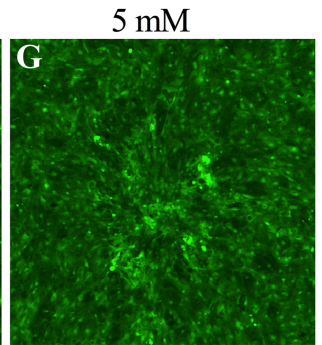

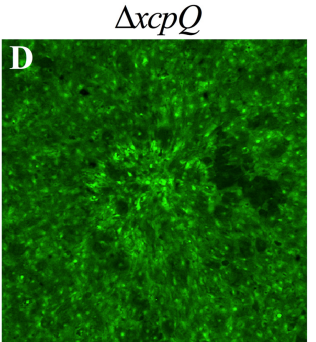

$\triangle x c p Q+\mathrm{pMQ644}$ $50 \mathrm{mM}$

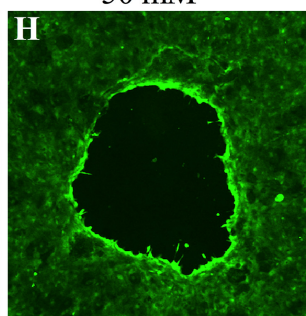

FIG $9 \mathrm{XcpQ}$ is required for the inhibition of stratified corneal cell migration in vitro. Shown are representative images of cells stained with the vital stain Calcein AM and imaged by confocal microscopy. (A to C) A cell-free zone (black circle) in layers of a stratified human corneal cell line (A) closes rapidly when treated with LB medium and incubated for $24 \mathrm{~h} \mathrm{(B),} \mathrm{but} \mathrm{this} \mathrm{migration} \mathrm{is} \mathrm{inhibited} \mathrm{by} \mathrm{filtrates} \mathrm{from} \mathrm{PA14} \mathrm{cultures} \mathrm{grown} \mathrm{in} \mathrm{LB} \mathrm{medium} \mathrm{(C).} \mathrm{(D)}$ Filtrates from isogenic $\triangle x c p Q$ mutants were unable to impede cell migration. (E and F) D-Xylose (50 mM)-induced expression of $g f p$ from $\mathrm{pMQ} 578$ did not alter the migration phenotypes of cells exposed to PA14 or $\triangle x c p Q$ mutant filtrates. $(\mathrm{G}$ and $\mathrm{H}$ ) Culture filtrates from the $\triangle x c p Q$ mutant with the wild-type $x c p Q$ gene on a plasmid (pMQ644) that had been grown in LB medium with $5 \mathrm{mM}$ D-xylose were unable to inhibit cell migration (G), but those grown with $50 \mathrm{mM}$ D-xylose were complemented for the cell migration inhibition-defective phenotype $(H)$. All cultures were grown to stationary phase and were adjusted to an $\mathrm{OD}_{600}$ of 2 with fresh $\mathrm{LB}$, and bacteria were removed by centrifugation and filtration.

\section{DISCUSSION}

This study introduces a new inducible promoter system for pseudomonads. The new $P_{x u t}$ promoter had no detectable function in $E$. coli. This could be considered a disadvantage of the $P_{x u t}$ promoter, because one cannot use the same plasmid construct to express genes in E. coli and a Pseudomonas species. However, since plasmids are almost exclusively passed through E. coli before moving into Pseudomonas species, genes that are toxic to $E$. coli are likely to be more easily cloned with $P_{x u t}$ than with other promoter systems that might have leaky expression in E. coli. For $P$. aeruginosa, the $P_{x u t}$ promoter appeared to be largely equivalent to $P_{B A D}$ although it was leakier, and there was a tendency toward higher expression with $P_{x u t}$ on a population basis (Fig. 2) and in GFP-positive fluorescent cells, but this did not reach significance (Fig. 7 and 8). In $P$. fluorescens, the $P_{x u t}$ promoter performed better than $P_{B A D}$ with respect to maximal expression levels and required a lower concentration of inducer for expression (Fig. 2C, 7, and 8). One caveat in comparing the $P_{x u t}$ and $P_{B A D}$ promoters in these Pseudomonas species is that pMQ80 has a pRO1600 origin of replication and pMQ578 has a pBBR1 origin of replication. While these have been reported to support similar copy numbers (20-22), this feature is an additional variable. In addition to xylose, $P_{x u t}$ can be activated by ribose (14), raising the possibility that the $P_{x u t}$ promoter can be fine-tuned with these alternative carbohydrate inducers.

Pseudomonas species have been suggested for industrial production and bioremediation of molecules, including, but not limited to, $\beta$-peptides (23), polyhydroxyalkanoates (24), phenazine-1-carboxyamide (25), proteases $(26,27)$, pseudofactin (28), rhamnolipids (29-31), silver nanoparticles (32), and toluene (33). The ability of $P_{x u t}$ to activate gene expression in the majority of cells and its relative strength in $P$. fluorescens compared to $\mathrm{P}_{B A D}$ suggest that it may be useful for large-scale gene synthetic applications. These advantages are further strengthened by the low cost of $D$-xylose relative to other inducers; L-arabinose and isopropyl- $\beta$-D-thiogalactopyranoside (IPTG) cost 
TABLE 2 Primers and synthetic DNA sequences used in this study

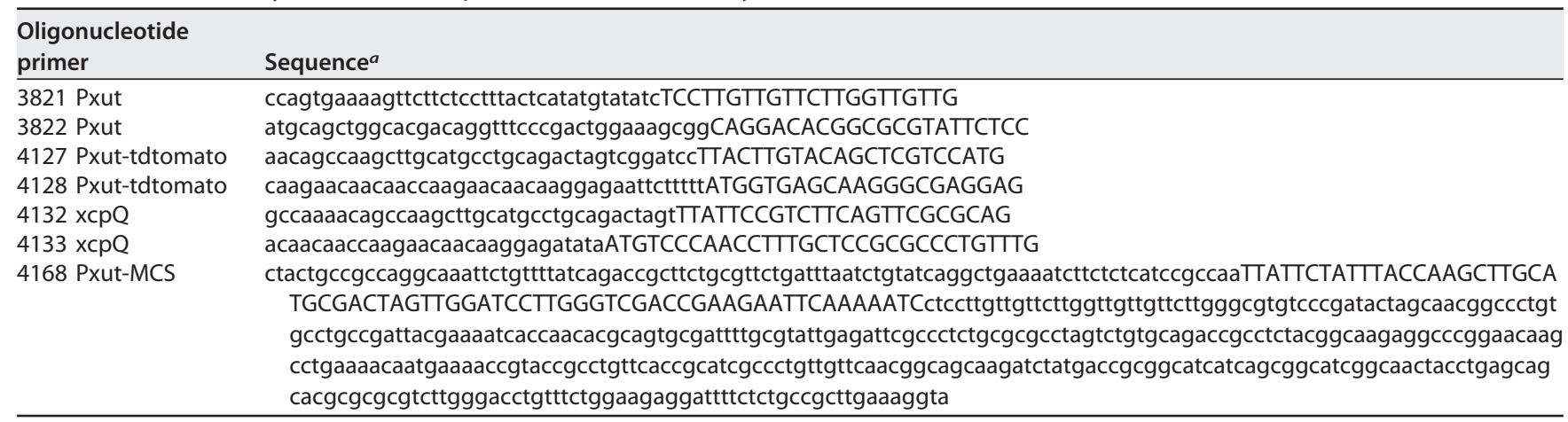

${ }^{a}$ Capital letters indicate sequence that directs priming, except for oligonucleotide 4168 , where capital letters indicate the sequence that replaced GFP on pMQ578. Lowercase letters indicate sequence that directs recombination.

approximately 10 times more to induce a culture (with $10 \mathrm{mM}$ sugar or $0.1 \mathrm{mM}$ IPTG). An additional benefit of $D$-xylose is that it is not usable as a carbon source by either of the Pseudomonas species tested, indicating that the D-xylose inducer will not be catabolized for energy and thereby eliminated from the culture over time.

Xylose-inducible plasmid systems have been developed for a number of other Gram-negative bacteria, such as Caulobacter crescentus (34), and for Gram-positive species, including Bacillus subtilis, Clostridioides difficile, Lactococcus lactis, Staphylococcus xylosus, and Streptomyces lividans (35-39). The xylose-responsive transcription factors for these systems include members of the AraC family, such as XutR, used in this study, Lacl, MarR, and the ROK family. The fold induction ranges from $\sim 10$-fold, as is the case with $C$. crescentus, up to several orders of magnitude for $B$. subtilis and $C$. difficile. While the fold induction values for the different systems are not clearly comparable, because the developers used different reporters, media, induction times, and other variables, taken at face value, they put $P_{x u t}$ in the low to middle range of these expression systems.

With regard to corneal epithelial wound closure, previous work has implicated lipopolysaccharide from E. coli and Serratia marcescens in the inhibition of corneal wound healing $(12,40)$. Unlike that of $P$. aeruginosa, the secreted inhibitory factor from S. marcescens was heat stabile (12). Work with the $P_{x u t}$ promoter in this study strongly implicated the type II secretion system of $P$. aeruginosa strain PA14 in allowing the bacterium to inhibit corneal epithelial wound closure, which may increase its ability to establish ocular infections.

In summary, we have created an episomal-plasmid-based, xylose-inducible expression system and tested it in $P$. aeruginosa and $P$. fluorescens. The $P_{x u t}$ promoter region, including the ribosome binding site and regulatory gene, spans $1,356 \mathrm{bp}$, in contrast to $>2,042$ bp for the rhaSR- $P_{\text {rhaB }}$ system, making $P_{x u t}$ well suited for use on an episome. The $P_{x u t}$ system is likely leakier without an inducer than lacla- $P_{\text {tac }}$ and $r$ haSR- $P_{\text {rhaB }}$, but this has yet to be tested in controlled experiments. Nevertheless, the $P_{x u t}$ system presented here should be useful for the inducible expression of genes in Pseudomonas species by itself or in conjunction with other inducible systems.

\section{MATERIALS AND METHODS}

Strains, media, and growth conditions. Bacterial strains and plasmids are listed in Table 1. Bacteria were grown in lysogeny broth (LB) (41) and were aerated on a TC-7 tissue culture roller (New Brunswick, Inc). P. aeruginosa strains are listed in Table 1 . Gentamicin was used at $10 \mu \mathrm{g} / \mathrm{ml}$ in E. coli and $30 \mu \mathrm{g} / \mathrm{ml}$ in Pseudomonas species to select for plasmids. Bacterial culture density was measured with a $1-\mathrm{cm}$ cuvette using a SpectraMax M3 plate reader, except where noted below.

Plasmid construction. Plasmids are listed in Table 1, and oligonucleotide primers and synthetic DNA sequences are listed in Table 2. Plasmids were made using yeast homologous recombination (8), except for pMQ652, and were verified by PCR and sequencing of junctions. The xutR gene and the intergenic region between $x u t R$ and $x u t A$ from the Pseudomonas fluorescens Pf0-1 genome were cloned along with gfpmut3 ( $g f p$ ) (42) from pMQ80 (8) to replace $P_{l a c}$ and $l a c Z \alpha$ from pMQ132 (11). The resulting plasmid, pMQ578, and all plasmids made in this study are listed in Table 1. One variant of pMQ578 was 
made in which gfp was replaced with tdtomato from pMQ414 (43) using primers 4127 and 4218; this variant was named pMQ643. For another variant, pMQ650, an artificial DNA sequence containing six restriction enzyme sites (EcoRl, Sall, BamHI, Spel, Sphl, and HindIII) and a sequence with stop codons in three frames was introduced using a 499-bp double-stranded DNA sequence listed as primer 4168 (gBlock; IDT, Inc.). The pMQ650 plasmid was sequenced using the PacBio platform (coverage of 32) by SNPSaurus (Eugene, OR). Last, pMQ652 was made by the digestion of pMQ650 with Sspl and Stul, which excises a 1.8-kba region containing the yeast replicon and the URA3 gene, followed by recircularization with T4 DNA ligase.

Fluorescence assays. Bacteria were grown as described above, and at various time points, samples were obtained for analysis. Aliquots $(150 \mu \mathrm{l})$ were read in $96-$ well plates with black opaque sides and clear bottoms (catalog no. 165305; Thermo Scientific Nunc). GFP fluorescence and tdTomato fluorescence were read with a BioTek Synergy 2 plate reader using 485/20 excitation and 516/20 emission filters for GFP and 545/40 excitation and 590/20 emission filters for tdTomato. Optical density was read at $600 \mathrm{~nm}$.

Flow cytometry analysis of GFP fluorescence. Bacteria were grown overnight with or without $10 \mathrm{mM}$ inducer, adjusted to an $\mathrm{OD}_{600}$ of 2, washed twice, and adjusted to an $\mathrm{OD}_{600}$ of 0.02 in phosphate-buffered saline (PBS) that had been filtered with a $0.22-\mu \mathrm{m}$ filter. Flow cytometric analysis was performed on a CytoFLEX LX instrument (Beckman Coulter, USA). Filtered PBS was used as a negative control for gating bacteria by forward scatter (FSC) and side scatter (SSC). Approximately $10^{5}$ cells were analyzed per genotype, and the experiments were repeated on five occasions. Bacteria of each species without the fluorescent plasmid were used as negative controls to determine the FSC threshold, as well as for background fluorescence cutoff. Software analysis was performed using FlowJo, version 10 (Becton, Dickinson, USA).

Corneal cell migration analysis. In vitro epithelial cell wound closure assays were performed as described previously (12) using human corneal limbal epithelial (HCLE) cells (44) and a commercial wound-healing assay kit (Oris; product no. CMAU101; Platypus Technologies, LLC). After stratified cell layers of HCLE cells were established (45), they were challenged with $50 \mu$ l of normalized bacterial culture filtrates or LB medium that was added to $100 \mu \mathrm{l}$ of culture medium overlaid on the cells. The tissue culture medium consisted of stratification medium or keratinocyte serum-free medium (catalog no. 10724-011; Gibco) supplemented with bovine pituitary extract $(25 \mu \mathrm{g} / \mathrm{ml}$ ), epidermal growth factor $(0.2 \mathrm{ng} / \mathrm{ml})$, and penicillin and streptomycin at $100 \mu \mathrm{g} / \mathrm{ml}$. Bacterial culture filtrates were made using overnight cultures of $P$. aeruginosa grown in LB medium with or without xylose and antibiotic and were incubated at $30^{\circ} \mathrm{C}$. Cultures were adjusted to an $\mathrm{OD}_{600}$ of 1.0 using fresh LB medium and were filtered with a $0.22-\mu \mathrm{m}$ filter (Mellex-GV polyvinylidene difluoride [PVDF]). After 20 to $24 \mathrm{~h}, \mathrm{HCLE}$ cells were rinsed with PBS and were stained using $0.5 \mu \mathrm{M}$ Calcein AM (catalog no. C3099; Invitrogen) for 15 min. Cells were imaged using an Olympus FluoView FV-1000 laser scanner confocal microscope with a $4 \times$ (numerical aperture $[N A], 0.3)$ objective and were analyzed with FluoView image-viewing software.

Bacterial length analysis. Bacteria were grown in LB medium with or without inducer (arabinose or xylose at $10 \mathrm{mM}$ ) for $24 \mathrm{~h}$. Bacteria were then imaged as described above, but using a $60 \times$ objective. Bacteria were measured using ImageJ software, and at least 50 cells were counted from two different experiments per group.

Statistical analysis. Experiments were performed at least three times, and data were analyzed with GraphPad Prism software using ANOVA, two-way ANOVA, and Student $t$ tests.

Data availability. The annotated pMQ650 plasmid sequence has been deposited in GenBank under accession number MT344942. The DNA sequences of the xutR and $P_{\text {xut }}$ regions from pMQ578, corresponding to genome coordinates 2656767 to 2656949 from the PfO-1 genome, have been deposited in GenBank under accession number MN857504.

\section{SUPPLEMENTAL MATERIAL}

Supplemental material is available online only.

SUPPLEMENTAL FILE 1, PDF file, 1 MB.

\section{ACKNOWLEDGMENTS}

We thank Nancy Baker for expert help with flow cytometry and George O'Toole at Dartmouth Medical School for gifts of strains.

This study was supported by the Charles T. Campbell Laboratory of Ophthalmic Microbiology, NIH grants EY027331 (to R.M.Q.S.) and EY08098 (Core Grant for Vision Research), and the Eye and Ear Foundation of Pittsburgh, as well as by unrestricted funds from Research to Prevent Blindness.

\section{REFERENCES}

1. Lyczak JB, Cannon CL, Pier GB. 2000. Establishment of Pseudomonas aeruginosa infection: lessons from a versatile opportunist. Microbes Infect 2:1051-1060. https://doi.org/10.1016/s1286-4579(00) 01259-4.

2. Martinez-Gil M, Ramos C. 2018. Role of cyclic di-GMP in the bacterial virulence and evasion of the plant immunity. Curr Issues Mol Biol 25:199-222. https://doi.org/10.21775/cimb.025.199.

3. Moradali MF, Ghods S, Rehm BH. 2017. Pseudomonas aeruginosa lifestyle: a paradigm for adaptation, survival, and persistence. Front Cell Infect Microbiol 7:39. https://doi.org/10.3389/fcimb.2017.00039. 
4. O'Callaghan R, Caballero A, Tang A, Bierdeman M. 2019. Pseudomonas aeruginosa keratitis: protease IV and PASP as corneal virulence mediators. Microorganisms 7:281. https://doi.org/10.3390/microorganisms 7090281.

5. Kim J, Salvador M, Saunders E, González J, Avignone-Rossa C, Jiménez Jl. 2016. Properties of alternative microbial hosts used in synthetic biology: towards the design of a modular chassis. Essays Biochem 60:303-313. https://doi.org/10.1042/EBC20160015.

6. Martínez-García E, de Lorenzo V. 2019. Pseudomonas putida in the quest of programmable chemistry. Curr Opin Biotechnol 59:111-121. https:// doi.org/10.1016/j.copbio.2019.03.012.

7. Newman JR, Fuqua C. 1999. Broad-host-range expression vectors that carry the L-arabinose-inducible Escherichia coli araBAD promoter and the araC regulator. Gene 227:197-203. https://doi.org/10.1016/s0378-1119 (98)00601-5.

8. Shanks RMQ, Caiazza NC, Hinsa SM, Toutain CM, O'Toole GA. 2006. Saccharomyces cerevisiae-based molecular tool kit for manipulation of genes from gram-negative bacteria. Appl Environ Microbiol 72: 5027-5036. https://doi.org/10.1128/AEM.00682-06.

9. Qiu D, Damron FH, Mima T, Schweizer HP, Yu HD. 2008. PBAD-based shuttle vectors for functional analysis of toxic and highly regulated genes in Pseudomonas and Burkholderia spp. and other bacteria. Appl Environ Microbiol 74:7422-7426. https://doi.org/10.1128/AEM.01369-08.

10. Meisner J, Goldberg JB. 2016. The Escherichia coli rhaSR-PrhaBAD inducible promoter system allows tightly controlled gene expression over a wide range in Pseudomonas aeruginosa. Appl Environ Microbiol 82: 6715-6727. https://doi.org/10.1128/AEM.02041-16.

11. Shanks RMQ, Kadouri DE, MacEachran DP, O'Toole GA. 2009. New yeast recombineering tools for bacteria. Plasmid 62:88-97. https://doi.org/10 .1016/j.plasmid.2009.05.002.

12. Brothers KM, Stella NA, Hunt KM, Romanowski EG, Liu X, Klarlund JK, Shanks RM. 2015. Putting on the brakes: bacterial impediment of wound healing. Sci Rep 5:14003. https://doi.org/10.1038/srep14003.

13. Altschul SF, Gish W, Miller W, Myers EW, Lipman DJ. 1990. Basic local alignment search tool. J Mol Biol 215:403-410. https://doi.org/10.1016/ S0022-2836(05)80360-2.

14. Liu Y, Rainey PB, Zhang XX. 2015. Molecular mechanisms of xylose utilization by Pseudomonas fluorescens: overlapping genetic responses to xylose, xylulose, ribose and mannitol. Mol Microbiol 98:553-570. https://doi.org/10.1111/mmi.13142.

15. Khlebnikov A, Datsenko KA, Skaug T, Wanner BL, Keasling JD. 2001. Homogeneous expression of the $\mathrm{P}_{\mathrm{BAD}}$ promoter in Escherichia coli by constitutive expression of the low-affinity high-capacity AraE transporter. Microbiology 147:3241-3247. https://doi.org/10.1099/00221287 -147-12-3241.

16. Khlebnikov A, Risa O, Skaug T, Carrier TA, Keasling JD. 2000. Regulatable arabinose-inducible gene expression system with consistent control in all cells of a culture. J Bacteriol 182:7029-7034. https://doi.org/10.1128/ jb.182.24.7029-7034.2000.

17. Siegele DA, Hu JC. 1997. Gene expression from plasmids containing the araBAD promoter at subsaturating inducer concentrations represents mixed populations. Proc Natl Acad Sci U S A 94:8168-8172. https://doi .org/10.1073/pnas.94.15.8168.

18. Filloux A. 2011. Protein secretion systems in Pseudomonas aeruginosa: an essay on diversity, evolution, and function. Front Microbiol 2:155. https://doi.org/10.3389/fmicb.2011.00155.

19. Qu Y, Olonisakin T, Bain W, Zupetic J, Brown R, Hulver M, Xiong Z, Tejero J, Shanks RM, Bomberger JM, Cooper VS, Zegans ME, Ryu H, Han J, Pilewski J, Ray A, Cheng Z, Ray P, Lee JS. 2018. Thrombospondin-1 protects against pathogen-induced lung injury by limiting extracellular matrix proteolysis. JCI Insight 3:96914. https://doi.org/10.1172/jci.insight .96914.

20. Farinha MA, Kropinski AM. 1989. Construction of broad-host-range vectors for general cloning and promoter selection in Pseudomonas and Escherichia coli. Gene 77:205-210. https://doi.org/10.1016/0378-1119 (89)90068-1.

21. Mi J, Sydow A, Schempp F, Becher D, Schewe H, Schrader J, Buchhaupt M. 2016. Investigation of plasmid-induced growth defect in Pseudomonas putida. J Biotechnol 231:167-173. https://doi.org/10.1016/j.jbiotec .2016.06.001.

22. Schweizer HP. 1991. Escherichia-Pseudomonas shuttle vectors derived from pUC18/19. Gene 97:109-121. https://doi.org/10.1016/0378-1119 (91)90016-5

23. Sallam A, Kast A, Przybilla S, Meiswinkel T, Steinbuchel A. 2009. Biotech- nological process for production of $\beta$-dipeptides from cyanophycin on a technical scale and its optimization. Appl Environ Microbiol 75:29-38. https://doi.org/10.1128/AEM.01344-08.

24. Borrero-de Acuna JM, Hidalgo-Dumont C, Pacheco N, Cabrera A, Poblete-Castro I. 2017. A novel programmable lysozyme-based lysis system in Pseudomonas putida for biopolymer production. Sci Rep 7:4373. https://doi.org/10.1038/s41598-017-04741-2.

25. Peng H, Zhang P, Bilal M, Wang W, Hu H, Zhang X. 2018. Enhanced biosynthesis of phenazine-1-carboxamide by engineered Pseudomonas chlororaphis HT66. Microb Cell Fact 17:117. https://doi.org/10.1186/ s12934-018-0962-3.

26. Chakraborty R, Srinivasan M. 1992. Production and regulation of a thermostable protease by Pseudomonas sp. B45. Acta Microbiol Hung 39:181-191.

27. Prieto A, Escapa IF, Martinez V, Dinjaski N, Herencias C, de la Pena F, Tarazona N, Revelles O. 2016. A holistic view of polyhydroxyalkanoate metabolism in Pseudomonas putida. Environ Microbiol 18:341-357. https://doi.org/10.1111/1462-2920.12760.

28. Biniarz P, Coutte F, Gancel F, Łukaszewicz M. 2018. High-throughput optimization of medium components and culture conditions for the efficient production of a lipopeptide pseudofactin by Pseudomonas fluorescens BD5. Microb Cell Fact 17:121. https://doi.org/10.1186/s12934 $-018-0968-x$.

29. Henkel M, Geissler M, Weggenmann F, Hausmann R. 2017. Production of microbial biosurfactants: status quo of rhamnolipid and surfactin towards large-scale production. Biotechnol J 12:1600561. https://doi.org/ 10.1002/biot.201600561.

30. Jiang J, Zu Y, Li X, Meng Q, Long X. 2019. Recent progress towards industrial rhamnolipids fermentation: process optimization and foam control. Bioresour Technol 298:122394. https://doi.org/10.1016/j.biortech.2019.122394.

31. Sood U, Singh DN, Hira P, Lee JK, Kalia VC, Lal R, Shakarad M. 2020. Rapid and solitary production of mono-rhamnolipid biosurfactant and biofilm inhibiting pyocyanin by a taxonomic outlier Pseudomonas aeruginosa strain CR1. J Biotechnol 307:98-106. https://doi.org/10.1016/j.jbiotec .2019.11.004.

32. Punjabi K, Yedurkar S, Doshi S, Deshapnde S, Vaidya S. 2017. Biosynthesis of silver nanoparticles by Pseudomonas spp. isolated from effluent of an electroplating industry. IET Nanobiotechnol 11:584-590. https://doi .org/10.1049/iet-nbt.2016.0172.

33. Miller ES, Jr, Peretti SW. 2002. Toluene bioconversion to $p$-hydroxybenzoate by fed-batch cultures of recombinant Pseudomonas putida. Biotechnol Bioeng 77:340-351. https://doi.org/10.1002/bit.10071.

34. Meisenzahl AC, Shapiro L, Jenal U. 1997. Isolation and characterization of a xylose-dependent promoter from Caulobacter crescentus. J Bacteriol 179:592-600. https://doi.org/10.1128/jb.179.3.592-600.1997.

35. Bhavsar AP, Zhao X, Brown ED. 2001. Development and characterization of a xylose-dependent system for expression of cloned genes in Bacillus subtilis: conditional complementation of a teichoic acid mutant. Appl Environ Microbiol 67:403-410. https://doi.org/10.1128/AEM.67.1.403-410.2001.

36. Miyoshi A, Jamet E, Commissaire J, Renault P, Langella P, Azevedo V. 2004. A xylose-inducible expression system for Lactococcus lactis. FEMS Microbiol Lett 239:205-212. https://doi.org/10.1016/j.femsle.2004.08.018.

37. Nariya H, Miyata S, Kuwahara T, Okabe A. 2011. Development and characterization of a xylose-inducible gene expression system for Clostridium perfringens. Appl Environ Microbiol 77:8439-8441. https://doi .org/10.1128/AEM.05668-11.

38. Noguchi $Y$, Kashiwagi N, Uzura A, Ogino C, Kondo A, lkeda H, Sota M. 2018. Development of a strictly regulated xylose-induced expression system in Streptomyces. Microb Cell Fact 17:151. https://doi.org/10.1186/ s12934-018-0991-y.

39. Wieland KP, Wieland B, Gotz F. 1995. A promoter-screening plasmid and xylose-inducible, glucose-repressible expression vectors for Staphylococcus carnosus. Gene 158:91-96. https://doi.org/10.1016/0378-1119(95)00137-u.

40. Eslani M, Movahedan A, Afsharkhamseh N, Sroussi H, Djalilian AR. 2014. The role of toll-like receptor 4 in corneal epithelial wound healing. Invest Ophthalmol Vis Sci 55:6108-6115. https://doi.org/10.1167/iovs.14-14736

41. Bertani G. 1951. Studies on lysogenesis. I. The mode of phage liberation by lysogenic Escherichia coli. J Bacteriol 62:293-300. https://doi.org/10 .1128/JB.62.3.293-300.1951.

42. Cormack BP, Valdivia RH, Falkow S. 1996. FACS-optimized mutants of the green fluorescent protein (GFP). Gene 173:33-38. https://doi.org/10 .1016/0378-1119(95)00685-0.

43. Mukherjee S, Brothers KM, Shanks RM, Kadouri DE. 2015. Visualizing Bdell- 
ovibrio bacteriovorus by using the tdTomato fluorescent protein. Appl Environ Microbiol 82:1653-1661. https://doi.org/10.1128/AEM.03611-15.

44. Gipson IK, Spurr-Michaud S, Argüeso P, Tisdale A, Ng TF, Russo CL. 2003. Mucin gene expression in immortalized human corneal-limbal and conjunctival epithelial cell lines. Invest Ophthalmol Vis Sci 44:2496-2506. https://doi.org/10.1167/iovs.02-0851.

45. Block ER, Matela AR, SundarRaj N, Iszkula ER, Klarlund JK. 2004. Wounding induces motility in sheets of corneal epithelial cells through loss of spatial constraints: role of heparin-binding epidermal growth factor-like growth factor signaling. J Biol Chem 279:24307-24312. https://doi.org/ 10.1074/jbc.M401058200.

46. Miller VL, Mekalanos JJ. 1988. A novel suicide vector and its use in construction of insertion mutations: osmoregulation of outer membrane proteins and virulence determinants in Vibrio cholerae requires toxR. J Bacteriol 170:2575-2583. https://doi.org/10.1128/jb.170.6.2575-2583.1988.
47. Holloway BW. 1955. Genetic recombination in Pseudomonas aeruginosa. J Gen Microbiol 13:572-581. https://doi.org/10.1099/00221287 -13-3-572.

48. Rahme LG, Stevens EJ, Wolfort SF, Shao J, Tompkins RG, Ausubel FM. 1995. Common virulence factors for bacterial pathogenicity in plants and animals. Science 268:1899-1902. https://doi.org/10.1126/science.7604262.

49. Kowalski RP, Pandya AN, Karenchak LM, Romanowski EG, Husted RC, Ritterband DC, Shah MK, Gordon YJ. 2001. An in vitro resistance study of levofloxacin, ciprofloxacin, and ofloxacin using keratitis isolates of Staphylococcus aureus and Pseudomonas aeruginosa. Ophthalmology 108: 1826-1829. https://doi.org/10.1016/S0161-6420(01)00724-2.

50. Deflaun MF, Tanzer AS, McAteer AL, Marshall B, Levy SB. 1990. Development of an adhesion assay and characterization of an adhesiondeficient mutant of Pseudomonas fluorescens. Appl Environ Microbiol 56:112-119. https://doi.org/10.1128/AEM.56.1.112-119.1990. 